Research paper

\title{
Subthalamic beta oscillations correlate with dopaminergic degeneration in experimental parkinsonism
}

\author{
Jens K. Haumesser ${ }^{\text {a }}$, Maximilian H. Beck ${ }^{\text {a }}$, Franziska Pellegrini ${ }^{\text {a }}$, Johanna Kühn ${ }^{\text {a }}$, Wolf- \\ Julian Neumann ${ }^{a}$, Jennifer Altschüler ${ }^{a}$, Daniel Harnack ${ }^{a, b}$, Andreas Kupsch ${ }^{c}$, \\ Vadim V. Nikulin ${ }^{\text {d, Andrea A. Kühn }}{ }^{\text {a,e, }}$, Christoph van Riesen ${ }^{\text {a, e, f, g, , , } 1 ~}$ \\ ${ }^{a}$ Movement Disorders and Neuromodulation Unit, Department of Neurology, Charité University Medicine Berlin, Berlin, Germany \\ ${ }^{\mathrm{b}}$ Department of Neurologic Rehabilitation, Kliniken Beelitz, Beelitz-Heilstätten, Germany \\ ${ }^{\mathrm{c}}$ Clinic of Neurology and Stereotactic Neurosurgery, Otto von Guericke University, Magdeburg, Germany \\ ${ }^{\mathrm{d}}$ Department of Neurology, Max-Planck-Institute for Human Cognitive and Brain Sciences, Leipzig, Germany \\ ${ }^{\text {e }}$ German Center for Neurodegenerative Diseases (DZNE), Germany \\ ${ }^{\mathrm{f}}$ Berlin Institute of Health (BIH), Berlin, Germany \\ ${ }^{\mathrm{g}}$ Department of Neurology, University Medicine Göttingen, Göttingen, Germany
}

\section{A R T I C L E I N F O}

\section{Keywords:}

Parkinson's disease

Beta oscillations

Neurodegeneration

Basal ganglia

\begin{abstract}
A B S T R A C T
Excessive beta activity has been shown in local field potential recordings from the cortico-basal ganglia loop of Parkinson's disease patients and in its various animal models. Recent evidence suggests that enhanced beta oscillations may play a central role in the pathophysiology of the disorder and that beta activity may be directly linked to the motor impairment. However, the temporal evolution of exaggerated beta oscillations during the ongoing dopaminergic neurodegeneration and its relation to the motor impairment and histological changes are still unknown. We investigated motor behavioral, in-vivo electrophysiological (subthalamic nucleus, motor cortex) and histological changes (striatum, substantia nigra compacta) 2, 5, 10 and 20-30 days after a 6-hydroxydopamine injection into the medial forebrain bundle in Wistar rats.

We found strong correlations between subthalamic beta power and motor impairment. No correlation was found for beta power in the primary motor cortex. Only subthalamic but not cortical beta power was strongly correlated with the histological markers of the dopaminergic neurodegeneration. Significantly increased subthalamic beta oscillations could be detected before this increase was found in primary motor cortex. At the latest observation time point, a significantly higher percentage of long beta bursts was found. Our study is the first to show a strong relation between subthalamic beta power and the dopaminergic neurodegeneration. Thus, we provide additional evidence for an important pathophysiological role of subthalamic beta oscillations and prolonged beta bursts in Parkinson's disease.
\end{abstract}

\section{Introduction}

Enhanced beta oscillations (13-30 Hz) have been demonstrated in local field potentials (LFP) recorded from the motor cortex and basal ganglia of Parkinson's disease (PD) patients and in different animal models of the disease (Brown et al. 2001; Kuhn et al. 2005; Kuhn et al. 2004; Leblois et al. 2007; Levy et al. 2002; Sharott et al. 2005; Shimamoto et al. 2013). Beta oscillations are suppressed by symptomatic treatments such as levodopa and deep brain stimulation (DBS) of the subthalamic nucleus (STN) (Doyle et al. 2005; Eusebio et al. 2009; Kuhn et al. 2006; Kuhn et al. 2009). The treatment-induced reduction of beta power closely correlates with the amelioration of akinesia and rigidity in PD patients (Kuhn et al. 2006; Kuhn et al. 2009; Ray et al. 2008; Weinberger et al. 2006). Resting state STN beta activity relates to bradykinesia and rigidity (Neumann et al. 2016; van Wijk et al. 2016) that can be found even after chronic DBS (Neumann et al. 2017). Additionally, DBS at beta frequencies results in a further deterioration of motor impairment (Chen et al. 2011; Eusebio et al. 2008). Consequently, it has

\footnotetext{
* Corresponding author at: Movement Disorders and Neuromodulation Unit, Department of Neurology, Charité University Medicine Berlin, Berlin, Germany.

E-mail address: christoph.van-riesen@med.uni-goettingen.de (C. van Riesen).

1 Andrea A. Kühn and Christoph van Riesen contributed equally to this work.
} 
been hypothesized that beta oscillations might be directly linked to motor impairment in PD (Eusebio and Brown 2009; Timmermann and Fink 2011). This theory is based on the idea that an abnormally high synchronization in the beta band might compromise the information flow and output signals of the cortico-basal ganglia loop. Further investigation of beta oscillations revealed that beta activity occurs not as a continuous signal but rather in bursts of activity (Feingold et al. 2015). While short beta bursts appear to play a physiological role in the corticobasal ganglia loop, patient studies found a close link between longer bursts and rigidity and akinesia in PD (Tinkhauser et al. 2017a; Tinkhauser et al. 2017b). Moreover, levodopa treatment in these patients resulted in a reduction of long beta bursts (Lofredi et al. 2018b; Tinkhauser et al. 2017b). Therefore, it is currently investigated if beta activity can be scrutinized as a feedback biomarker for adaptive DBS treatment (Arlotti et al. 2018; Little et al. 2015; Little et al. 2013; Priori et al. 2013). Despite this potential clinical application of beta activity as a biomarker, its role in the pathophysiology of PD is still debated (Brown 2007; Stein and Bar-Gad 2013), several studies even question the importance of beta activity in PD (Connolly et al. 2015; Degos et al. 2009; Leblois et al. 2007; Muralidharan et al. 2016). Since beta oscillations are primarily studied in PD patients suffering from advanced disease stages, little is known on the interrelation of beta activity and the progress of dopaminergic neurodegeneration and motor symptoms. Although it is widely accepted that PD is a network disorder involving the cortico-basal ganglia-thalamo-cortical loop, it is not yet clear where beta activity is generated in the motor network (Hammond et al. 2007; Oswal et al. 2013).

In order to further clarify the significance of beta oscillations and beta bursts for the pathophysiology of $\mathrm{PD}$, we investigated the temporal evolution of subthalamic and cortical beta power and beta burst activity, motor behavior (akinesia) and the striatal and nigral dopaminergic neurodegeneration in the progressive 6-hydroxydopamine (6-OHDA) rat model of PD.

\section{Material and methods}

\subsection{Animals and materials}

Experimental procedures were carried out on male Wistar rats (Harlan Winkelmann, Germany) and were conducted in accordance to the German Animal Welfare Act (last revised in 2014), European regulations (2010/63/EU) and FELASA guidelines. All experiments were approved in advance by German animal welfare authorities. Every effort was made to minimize group sizes and experiment-related harm. Animals were kept in standard housing conditions with a $12 \mathrm{~h} \mathrm{light/dark}$ cycle with lights on at 7 a.m. Food and water were available ad libitum. All materials were obtained from Sigma-Aldrich, Germany, unless stated otherwise. All stereotactic coordinates were measured in millimeters to the bregma (Paxinos and Watson 2013).

\subsection{Experimental design}

The study consisted of five groups: four experimental groups with different time intervals between the injection of 6-OHDA and the electrophysiological recordings and a control group in which animals were injected the solvent only (Figs. 1,3). In the 6-OHDA group experiments started with a characterization of motor behavior, immediately followed by the injection of the neurotoxin 6-hydroxydopamine (6-OHDA) into the left medial forebrain bundle. After an interval of $2,5,10$ or $20-30$ days, the motor behavioral tests were repeated. Thereafter, animals underwent simultaneous in vivo electrophysiological recordings from the primary motor cortex and the subthalamic nucleus under urethane anesthesia. Subsequently, the animals were sacrificed and the brains processed to assess the histological outcome parameters. The latest time point of the analysis was chosen to be between 20 and 30 days after the 6-OHDA injection, because the degeneration of the dopaminergic nigrostriatal system is completed 20 days after 6-OHDA injection (Blandini and Armentero 2012; Blandini et al. 2007; Sharott et al. 2005). Control animals received only the vehicle solution and the electrophysiological recordings were performed after an interval of 30 days. Afterwards the animals were sacrificed and their brains analyzed likewise to the 6-OHDA groups. A total of 46 rats were included in the study ( 2 days post injectionem (p.i.), 2 d p.i.: $n=10$; 5 d p.i.: $n=9$; 10 d p.i.: $n=$ 8; and 20-30d p.i.: $\mathrm{n}=10$; control $\mathrm{n}=9$ ).

\subsection{Unilateral 6-OHDA lesion}

Animals were anesthetized with a combination of fentanyl $(5 \mu \mathrm{g} / \mathrm{kg}$, s.c., Rotexmedica, Germany), medetomidine (150 $\mu \mathrm{g} / \mathrm{kg}$, s.c., Domitor ${ }^{\circledR}$, Provet AG, Germany) and midazolam (2 mg/kg, s.c., Hameln Pharma, Germany). The fur alongside the dorsal side of the head was shaved and the skin disinfected with 70\% ethanol. Rats were then placed in a stereotactic frame (David Kopf Instruments, CA, USA) and the head was fixed with atraumatic ear bars. Ophthalmic ointment (Bepanthen ${ }^{\mathrm{TM}}$, Bayer, Germany) was applied to prevent corneal dehydration. Respiratory rate and pedal withdrawal reflex were constantly monitored during

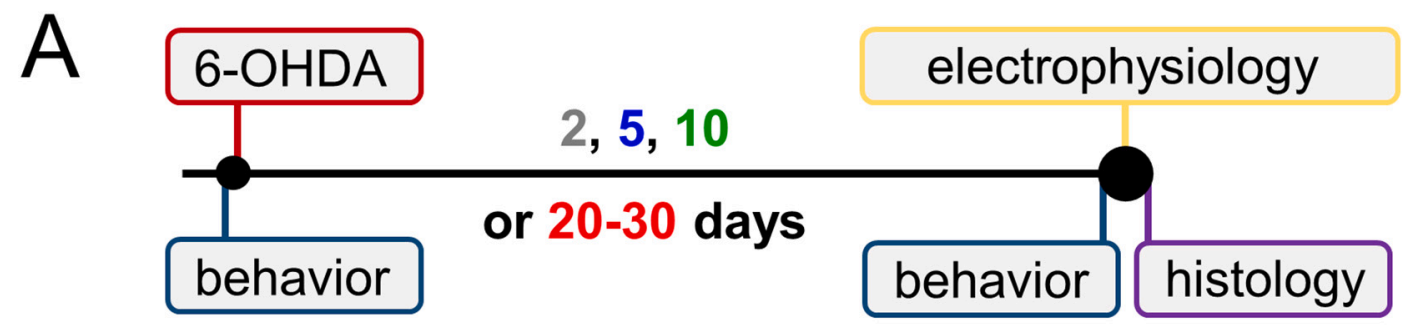

B

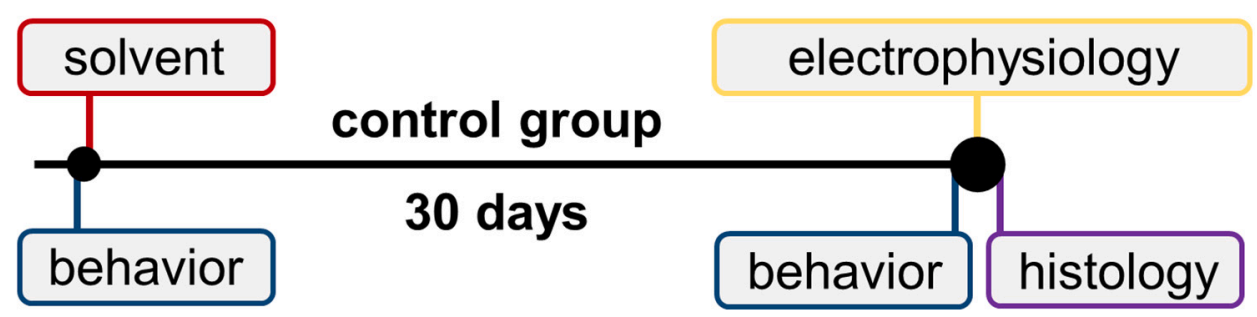

Fig. 1. Experimental design. A, 6-OHDA group. B, Control group. 
anesthesia. Body temperature was maintained at $37 \pm 0.5^{\circ} \mathrm{C}$ throughout surgery using a self-adjusting heating pad (CMA, Sweden). After surgical preparation of the skull bone, the head was precisely aligned to flat skull position.

Following a $1 \mathrm{~mm}$ craniotomy, a 33-gauge blunt-tip cannula, connected to a precision syringe pump (NanoFil ${ }^{\mathrm{TM}}$, Micro $4^{\mathrm{TM}}$, World Precision Instruments, FL, USA) was inserted into the left medial forebrain bundle (AP: -2.6 , ML: 1.6, DV: $-8.4 \mathrm{~mm}$ ). $1 \mu \mathrm{l}$ of the neurotoxin 6OHDA $(8 \mu \mathrm{g} / \mu \mathrm{l})$ was injected at a flow rate of $125 \mathrm{nl} / \mathrm{min}$ via a precision syringe pump (Micro $4^{\mathrm{TM}}$, World Precision Instruments, FL, USA). The cannula remained in place for $5 \mathrm{~min}$ after injection and was then withdrawn slowly. Surgical wound closure was performed and anesthesia was reversed using a combination of naloxone $(120 \mu \mathrm{g} / \mathrm{kg}$, s.c., B. Braun Melsungen AG, Germany), flumazenil (200 $\mu \mathrm{g} / \mathrm{kg}$, s.c., Inresa, Germany) and atipamezole (750 $\mu \mathrm{g} / \mathrm{kg}$, s.c., cp-pharma, Germany). Animals were administered the analgesic carprofen $(5 \mathrm{mg} / \mathrm{kg}$, s.c., Pfizer, Germany) for three postoperative days.

\subsection{Behavioral testing}

Motor outcome was assessed in all animals and documented with digital video. Two standard tests were used to detect asymmetry in forelimb use, the drag test and the cylinder test (Meredith and Kang 2006). For the cylinder test, rats were placed in a transparent acryl glass cylinder (height: $45 \mathrm{~cm}$, diameter: $20 \mathrm{~cm}$ ) without prior habituation (Schallert et al. 2000). During the rat's spontaneous vertical exploration of the cylinder walls, all contacts of the forepaws with the walls were counted. For the drag test, animals were dragged backwards by hand for the distance of $1 \mathrm{~m}$ at a speed of $10 \mathrm{~cm} / \mathrm{s}$ and adjusting steps were counted. In both tests, trials were carried out until at least one forepaw had reached a minimum of 15 contacts. Results are reported as relative ratios (\%) of the right (affected) to the left forelimb (unaffected side, = $100 \%)$.

\subsection{In vivo electrophysiological recordings under urethane anesthesia}

The same general surgical procedures were applied as described above. Anesthesia was induced with urethane $(1.3 \mathrm{~g} / \mathrm{kg}$, i.p.) between 7 and 8 a.m. All craniotomies were drilled to a diameter of $1 \mathrm{~mm}$, leaving the dura mater intact. Two custom $\mathrm{Ag} / \mathrm{AgCl}$ electrodes (spherical tip, diameter $200 \mu \mathrm{m}, 8 \mathrm{k} \Omega$ impedance) were inserted epidurally above the left M1 (AP: +3.0, ML: +3.0). For referencing, two identical electrodes were placed into the epidural space above the ipsi- and contralateral cerebellum (AP: -9.0 , ML: $+3.0 /-3.0$ ). Each pair of epidural electrodes was affixed with stainless steel micro-screws and acrylic dental cement (Technovit ${ }^{\circledR}$, Heraeus-Kulzer, Germany). For STN recordings, a pair of parylene insulated tungsten microelectrodes (Microprobes for Life Science, MD, USA; $1.5 \mathrm{M} \Omega$ impedance) was slowly inserted into the left hemisphere $1 \mathrm{~mm}$ above the target coordinates (AP: -3.6 , ML: +2.5 , DV: $-8.0 \mathrm{~mm}$ ). The final positioning of the electrodes in the STN was controlled by online evaluation of multi-unit activity as described previously (Haumesser et al. 2017).

Electrophysiological recordings were done in a Faraday cage using a programmable neural data acquisition system (Omniplex, Plexon, TX, USA). The recorded wide band signal was bandpass-filtered $(0.05-8000$ $\mathrm{Hz})$, amplified $(1750 \times)$, bandpass-filtered and downsampled (0.05-250 $\mathrm{Hz}, 1 \mathrm{kHz}$ ) for subsequent offline analysis.

\subsection{Histology and immunohistochemistry}

At the end of electrophysiological recordings, animals were perfused transcardially with $250 \mathrm{ml}$ of $0.1 \mathrm{M}$ phosphate buffered saline $(\mathrm{pH}=$ 7.4) and then $250 \mathrm{ml}$ of $4 \%$ paraformaldehyde. The brains were kept for $24 \mathrm{~h}$ in PFA for further fixation, and were then immersed in sucrose solutions of ascending concentrations (10-30\%) for cryoprotection. Afterwards, brains were frozen in 2-methylbutane at $-60{ }^{\circ} \mathrm{C}$ and then cryopreserved at $-80{ }^{\circ} \mathrm{C}$ until sectioning. The brains were then processed and cryotome sectioned to a thickness of $40 \mu \mathrm{m}$. The correct placement of the electrode was verified by cresyl violet staining and microscopic evaluation. Only animals with accurately placed electrodes, intact target areas and typical STN multi-unit activity were included in the study.

Representative serial sections from the striatum (STR) and substantia nigra pars compacta (SNc) were stained for tyrosine hydroxylase (TH) using a standard protocol (Steiner et al. 2008) with a primary anti-TH mouse antibody $(1: 10,000$, Sigma T1299) and a secondary anti-mouse antibody (1:200, Vector BA-9200). The TH antigen was then visualized via the avidin-biotin complex method and the chromogen 3,3'diaminobenzidine (DAB).

A representative TH-positive cell count for the SNc of both hemispheres was achieved using a Stereo Investigator System (MicroBrightField Bioscience, VT, USA) on a DMRE microscope (Leica, Germany). TH positive neurons of every 7 th section of the SNc were counted using the built-in optical dissector method of the Stereo-Investigator system.

Striatal fiber density was assessed as optical density using the MCID system (Northern Light R95 Precision Illuminator, MCID, UK; Cool Snap EZ Camera, Roper Scientific, Germany). Three representative coronal sections of the STR per animal, taken from the anterior (AP: +1.70 ), middle (AP: +0.20 ) and posterior (AP: -0.50 ) STR were analyzed. Measurements were taken from the dorsolateral STR, which is the subregion involved in the motor loop of the basal ganglia (Lindemann et al. 2013). The results of the left (6-OHDA lesioned) hemisphere are reported as relative cell count and normalized density (\%) of the right hemisphere (intact hemisphere $=100 \%$ ).

\subsection{Electrophysiological data analysis}

LFP data was analyzed using Spike2 (v8.02e, Cambridge Electronic, Design, UK) and MatLab (R2014B, MathWorks, MA, USA). In urethane anesthesia, two distinct cortical activation states can be found, slow wave activity (SWA) and the activated state (AS) (Abdi et al. 2015; Mallet et al. 2008a). In the SWA state, cortical LFPs are dominated by low-frequency high-amplitude oscillations (i.e. $0.05-2 \mathrm{~Hz}$ oscillations), while in periods of cortical activation (AS), the LFPs are characterized by faster oscillations with smaller amplitudes. The SWA brain state resembles that in natural non-rapid eye movement sleep, whereas the AS is considered to be similar to the cortical activity that can be found in awake and attentive subjects (Magill et al. 2000; Magill et al. 2006; Steriade 2000). Although the slow wave and the activated network state differ in certain aspects from the brain activity of non-anesthetized animals, the urethane anesthetized brain is a well-established model for characterizing LFPs in the cortico-basal ganglia loop without movement related artifacts (Magill et al. 2001; Mallet et al. 2008b). Since disease related changes of network activity, such as excessive beta oscillations, can solely be seen during cortical activation, we confined our analysis to periods of robust activated network states that were free of major artifacts (Beck et al. 2016; Mallet et al. 2008a). All activated states occurred spontaneously without sensory stimulation.

Power spectral densities of STN and M1 LFPs were calculated by fast Fourier transform (Hanning window, $1 \mathrm{~Hz}$ frequency resolution). One epoch of $50 \mathrm{~s}$ was analyzed per animal. Spectral density values of each power bin were normalized by the cumulative average of 8-12 and $31-90 \mathrm{~Hz}$ power. The beta frequency range was defined as frequency band from 13 to $30 \mathrm{~Hz}$. Power is expressed as normalized power in arbitrary units (a.u.). Significant peaks in power spectra were identified according to published criteria (Beck et al. 2016; Delaville et al. 2015).

For burst analysis, a wavelet transform was used to retrieve the timefrequency representation (Morlet wavelet, $5 \mathrm{~ms}$ steps, between 1 and $100 \mathrm{~Hz}$, resolution of $1 \mathrm{~Hz}$ ). For every Subject and time bin, we averaged the signal across frequencies from 13 to $30 \mathrm{~Hz}$ and smoothed it in time employing moving average $(200 \mathrm{~ms})$. Procedures for burst analysis were adapted from Tinkhauser and colleagues (Tinkhauser et al. 2017a; 
Tinkhauser et al. 2017b); see also: (Cagnan et al. 2019; Lofredi et al. 2018b). As the precise amplitudes of percentile-defined thresholds could vary between groups, we defined the threshold for STN and M1 separately as the 75th percentile of the amplitude distribution of all subjects and groups together. Thus, we applied the same threshold in every group, but used a different threshold for STN and M1 LFP recordings. Supplementary Fig. 1 illustrates the definition of bursts schematically: the signal was labeled as burst when exceeding the amplitude threshold (green line) for more than $100 \mathrm{~ms}$. The blue array indicates the burst duration, which is defined as the time from the point when the amplitude exceeds the threshold to the point when the amplitude undergoes the threshold again. The amplitude is defined as the peak amplitude of the burst (red array). A signal was labeled as short burst when exceeding a given amplitude threshold for $>100 \mathrm{~ms}$ and labeled as long duration burst when exceeding $350 \mathrm{~ms}$. All bursts longer than the average duration across all subjects plus 3 standard deviations were detected as outliers and rejected from further analysis. One animal from STN and one from M1 burst analysis were excluded due to artifacts. Percentage of long bursts and time spent in bursts of a $50 \mathrm{~s}$ epoch were calculated. Overlapping bursts were defined as simultaneous beta bursts in STN and M1 with minimum overlap duration of $200 \mathrm{~ms}$.

\subsection{Statistical analysis}

Statistical calculations were computed using GraphPad Prism (v6, GraphPad Software, CA, USA) and Matlab (R2014B, MathWorks, MA, USA). Each data set was tested for normal distribution. One-way ANOVA was used to test for differences between more than two groups followed by Dunnett's post hoc comparison and differences between two groups were calculated with the unpaired $t$-test. In cases in which the data did not meet the assumptions of normal distribution, Kruskal-Wallis test with Dunn's post hoc comparison, and the Mann-Whitney test were applied. The minimum significance level of all tests was defined to be alpha $<0.05(*<0.05 ; * *<0.01 ; * *<0.001 ; * * * * 0.0001)$. Unless stated otherwise, group data are expressed as the mean \pm standard error of the mean (SEM). Correlations and partial correlations between STN and M1 mean beta power (mean 13-30 Hz power) and histological and behavioral markers were calculated using Spearman's method.

\section{Results}

In the present study we investigated changes in motor behavior, in subthalamic and cortical LFPs, and in the histology of the nigrostriatal dopaminergic tract $2,5,10$ or 20-30 days following the injection of the neurotoxin 6-OHDA and compared the results to a control group.

\subsection{6-OHDA leads to a progressive degeneration of dopaminergic striatal fibers and nigral neurons}

The histological analysis of the STR and SNc revealed a progressive loss of TH-positive fibers and neurons over time (Fig. 2A, B). However, temporal dynamics of the neurodegeneration were different in these regions. Both in the STR and in the SNc, there were no significant changes in the histological measures 2 days after the 6-OHDA injection ( $2 \mathrm{~d}_{\mathrm{STR}}: 68.9 \pm 6.5 \%$; $2 \mathrm{~d}_{\mathrm{SNc}}$ : $98.90 \pm 6.54 \%$; Fig. $2 \mathrm{~B}$ ). For all later time points the striatal fiber density was significantly reduced in comparison to controls (5d: $20.97 \pm 5.32 \%, p<0.05$; $10 \mathrm{~d}$ : $3.49 \pm 1.40 \%, p<$ 0.0001; 20-30d: $1.76 \pm 3.08 \%, \mathrm{p}<0.0001$; Fig. 2B). In contrast, a statistically significant nigral cell loss could only be demonstrated in the groups of animals 10 and 20-30 days p.i. (5d: $72.67 \pm 6.02 \%, p>0.05$; 10d: $45.14 \pm 3.22 \%, p<0.001 ; 20-30 d: 16.24 \pm 1.82 \%$, $\mathrm{p}<0.0001$; Fig. 2B). At the latest investigated time point there was an almost total loss of TH-positive fibers in the STR and a very high degree of cell loss in the SNc in the 6-OHDA group (Fig. 2A, B). In control animals the nigrostriatal dopaminergic system was found to be intact (Fig. 2A, B).

\subsection{6-OHDA treated animals show early motor deficits}

Analysis of cylinder test data revealed a highly significant increase in mean forelimb use asymmetry already at day 2 p.i. $(24.27 \pm 7.51 \%$, p < 0.05; Fig. 2C). Thereafter, an additional progression in forelimb use asymmetry with a maximum at 10 and $20-30$ days p.i. was found $(5 \mathrm{~d}$ : $18.92 \pm 9.91 \%, p<0.01$; 10d: $7.02 \pm 3.70 \%, \mathrm{p}<0.001 ; 20$-30d: $9.53 \pm$ $4.243 \%, \mathrm{p}<0.0001$; Fig. $2 \mathrm{C}$ ). The assessment of forelimb use asymmetry with the drag test showed a severe and stable motor deficit starting at day 2 p.i. $(33.46 \pm 4.70 \%, \mathrm{p}<0.001 ; 5 \mathrm{~d}: 35.84 \pm 4.83 \%, \mathrm{p}<$ 0.01; 10d: $37.83 \pm 4.77 \%, \mathrm{p}<0.01$; 20-30d: $33.88 \pm 6.05 \%, \mathrm{p}<0.001$; Fig. 2C). Control animals exhibited no changes in motor behavior (Fig. 2C).

\subsection{Cortical and subthalamic beta oscillations increase over time, but with different temporal dynamics}

In the average power spectra of cortical as well as subthalamic LFPs distinct peaks in the low beta frequency range $(13-20 \mathrm{~Hz})$ could be identified (Fig. 3A-C). M1 mean beta power was increased in parkinsonian animals 20-30 days after 6-OHDA injection in comparison to controls (20-30d: $7.93 \pm 1.24$ a.u., $p<0.01$; Fig. 3A, B). There were no significant elevations of mean cortical beta power in the earlier groups (Fig. 3A, B). STN mean beta power was already significantly enhanced 10 days p.i. (10d: $5.35 \pm 0.32$ a.u., $\mathrm{p}<0.05$; Fig. 3A, B). A further increase in beta power could be seen $20-30$ days p.i. (20-30d: $6.80 \pm 0.66$ a.u., $\mathrm{p}<0.001$; Fig. 3A, B).

Although mean beta power was not significantly elevated at the earlier time points following the 6-OHDA injection, we identified a number of distinct spectral peaks in the beta frequency range already from day 2 p.i. in both targets (Fig. 3C). In M1 as well as in STN, the number of beta peaks per group increased over time with a maximum 20-30 days p.i. (STN: 7/10; M1: 6/10; Fig. 3C). The mean peak frequency was centered in the low beta range (STN: $16.86 \pm 3.19 \mathrm{~Hz}$; M1: $18.83 \pm 2.79 \mathrm{~Hz}$; Fig. 3C). There was no significant difference between the subthalamic and the cortical mean beta peak frequency (Fig. 3C). In the control group only one significant beta peak could be identified in the STN, whereas there was no peak in the power spectrum of the cortical LFP data. None of the animals had more than one spectral peak in the beta range. There were no significant peaks in any other frequency range.

\subsection{The percentage of longer beta bursts increases over time after 6- OHDA injection}

Beta bursts were binned into 6 categories: $100-225 \mathrm{~ms}, 225-350 \mathrm{~ms}$, $350-475 \mathrm{~ms}, 475-600 \mathrm{~ms}, 600-725 \mathrm{~ms}$ and $725-850 \mathrm{~ms}$. Overall, shorter bursts occurred more often than longer bursts (Fig. 4A). Both in STN and M1, we found a gradual decrease of very short bursts (100-225 $\mathrm{ms}$ ) with increasing days p.i. with the lowest number of bursts reached at 20-30 days p.i. (Fig. 4A). When re-grouping bursts into short ( $<350 \mathrm{~ms}$ ) and long $(>350 \mathrm{~ms}$ ), we found a significantly higher mean percentage of long bursts ( $>350 \mathrm{~ms}$ ) $20-30$ days p.i. in both structures (STN: $p<0.01$; M1: $\mathrm{p}<0.01$; Fig. 4B).

We found a significant increase of beta burst amplitude in lesioned animals $20-30$ days after the 6-OHDA injection in the STN $(p=0.0006)$ as well as in the M1 $(p=0.03$; not significant after Bonferronicorrection). The other experimental groups did not show a significant difference in amplitude in comparison to the control group.

The total burst time of a $50 \mathrm{~s}$ epoch expanded gradually from control animals to those 20-30 days p.i., showing a highly significant difference to the control group for M1 $(p<0.0001)$ as well as STN $(p<0.01$; Fig. 4D) at day 20-30 p.i.

Bursts from STN and M1 were considered as overlapping bursts if a minimum overlap duration of $200 \mathrm{~ms}$ was registered and expressed as relative number of overlapping bursts. The percentage of overlapping 

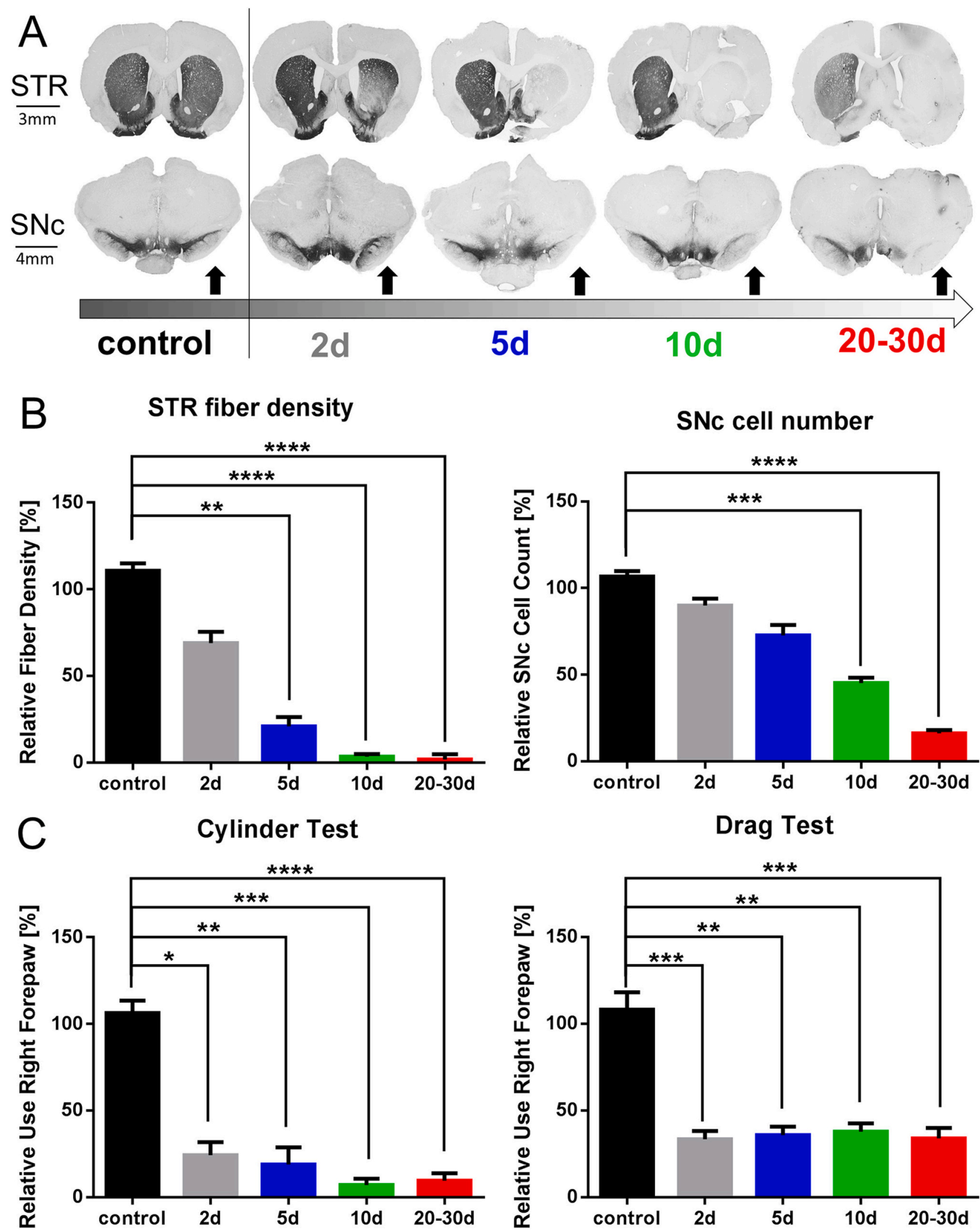

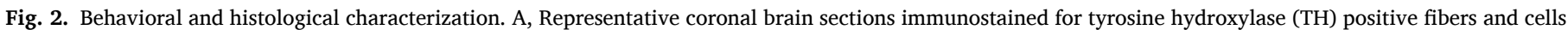

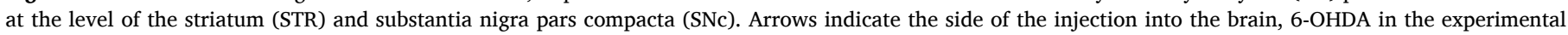

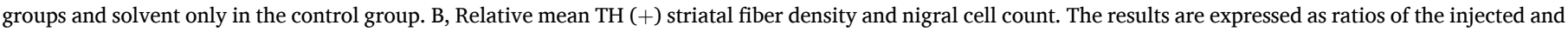

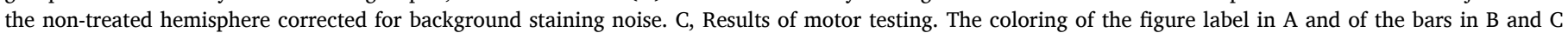

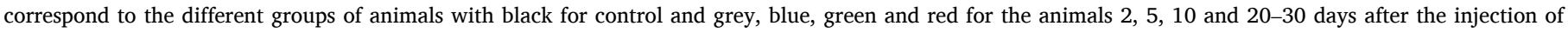
6-OHDA. 
A

\section{STN}

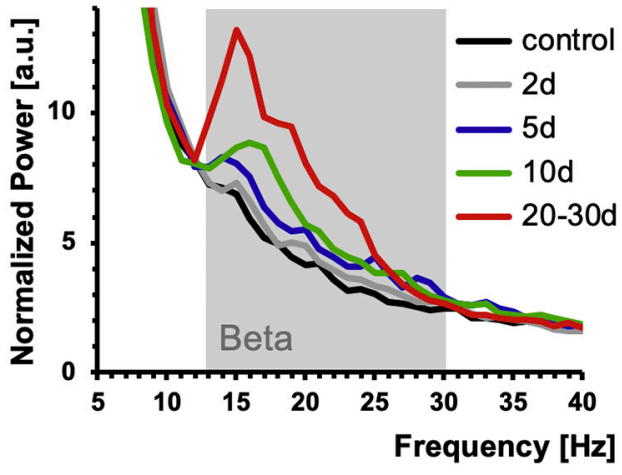

B

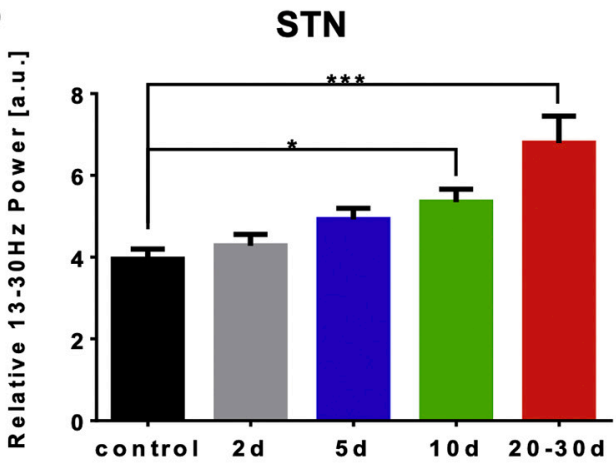

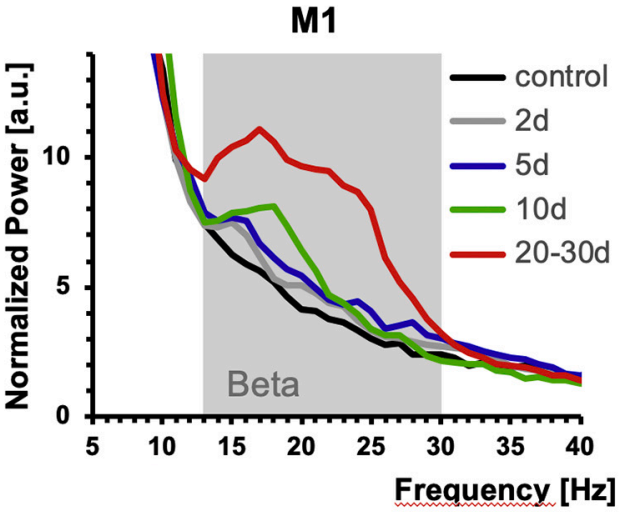

M1

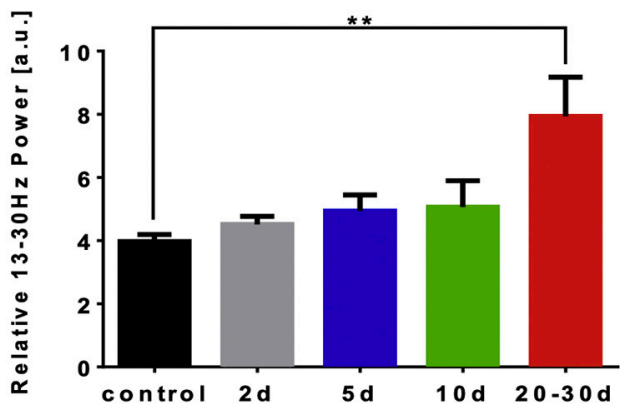

$\mathrm{C}$

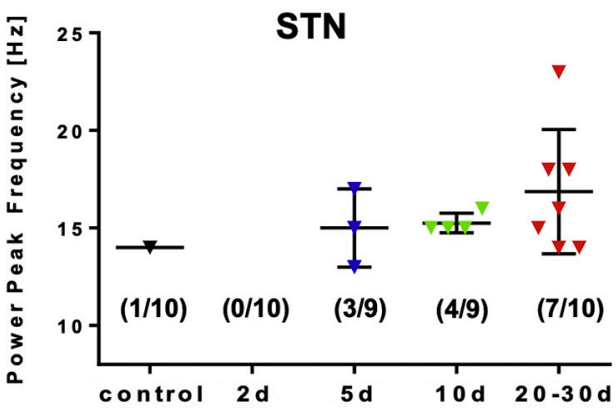

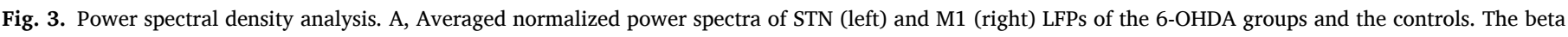

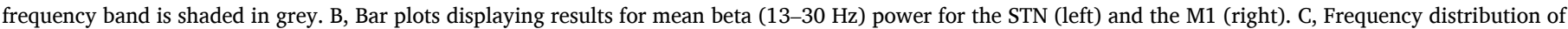

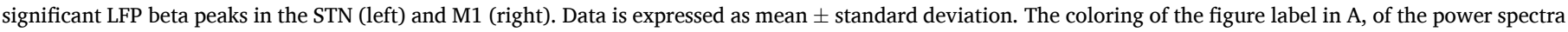

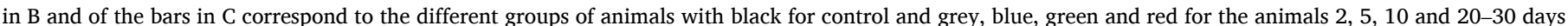
after the injection of 6-OHDA.

bursts was significantly higher than zero in all groups (experimental groups: $\mathrm{p}<0.0001$, control group: $\mathrm{p}<0.01$ ) and increased from a mean of $5 \%$ in control group to $19 \%$ at $20-30$ days p.i. (Fig. 4E), indicating an increase of concurrent beta transients across the corticosubthalamic axis.

\subsection{Subthalamic but not cortical beta oscillations correlate with markers} of neurodegeneration and motor impairment

Individual nigral cell loss and striatal fiber densities correlated strongly with motor impairment in the cylinder test (cyl-STR dens $_{0} \rho=$ $0.601, \mathrm{p}<0.0001$; cyl-SNc cell: $\rho=0.582$, $\mathrm{p}<0.0001$; Suppl. Fig. 2) and moderately with the scores of the drag test (drag-STR dens: $\rho=0.443, p<$ 0.01 ; drag-SNc cell: $\rho=0.437, \mathrm{p}<0.01$; Suppl. Fig. 2). Importantly, subthalamic beta power demonstrated a highly significant negative relation to striatal fiber density and SNc cell count (STN beta-STR: $\rho=$ $-0.544, \mathrm{p}<0.0001$; STN $\mathrm{Beta}_{\text {-SNc: }} \rho=-0.602$, $\mathrm{p}<0.0001$; Fig. 5 and
Suppl. Fig. 1A). Correlation coefficients for M1 beta power were significant, but weaker, with both histological parameters $\left(\mathrm{M}_{1} \mathrm{beta}_{\text {b }}-\mathrm{SNc}_{\text {cell }}\right.$ : $\rho=-0.400, \mathrm{p}<0.01$; M1 $1_{\text {beta }}-\mathrm{STR}: \rho=-0.336, p<0.05$; Fig. 5B). For further clarification we also performed partial Spearman correlation analysis in order to determine to what extent the correlation between mean beta power either in M1 or STN and histological findings could be explained by the changes in mean beta power in the other structure. This analysis showed that there was no significant correlation between M1 mean beta power and histological outcome parameters when controlling for beta power in STN $(p>0.05)$. Yet, the correlation between STN mean beta power and markers of dopaminergic neurodegeneration remained significant after controlling for M1 mean beta power (par-STN $\mathrm{beta}_{\text {- }} \mathrm{SNc}$ :

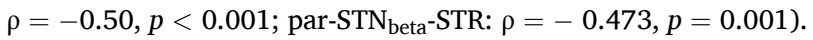

Next, we correlated cortical and subthalamic mean beta power with scores of motor impairment and found that STN mean beta power was significantly correlated with the extent of hemiakinesia in the cylinder test as well as in the drag test ( STN $_{\text {beta-cyl: } \rho=-0.337, p}<0.05$; 

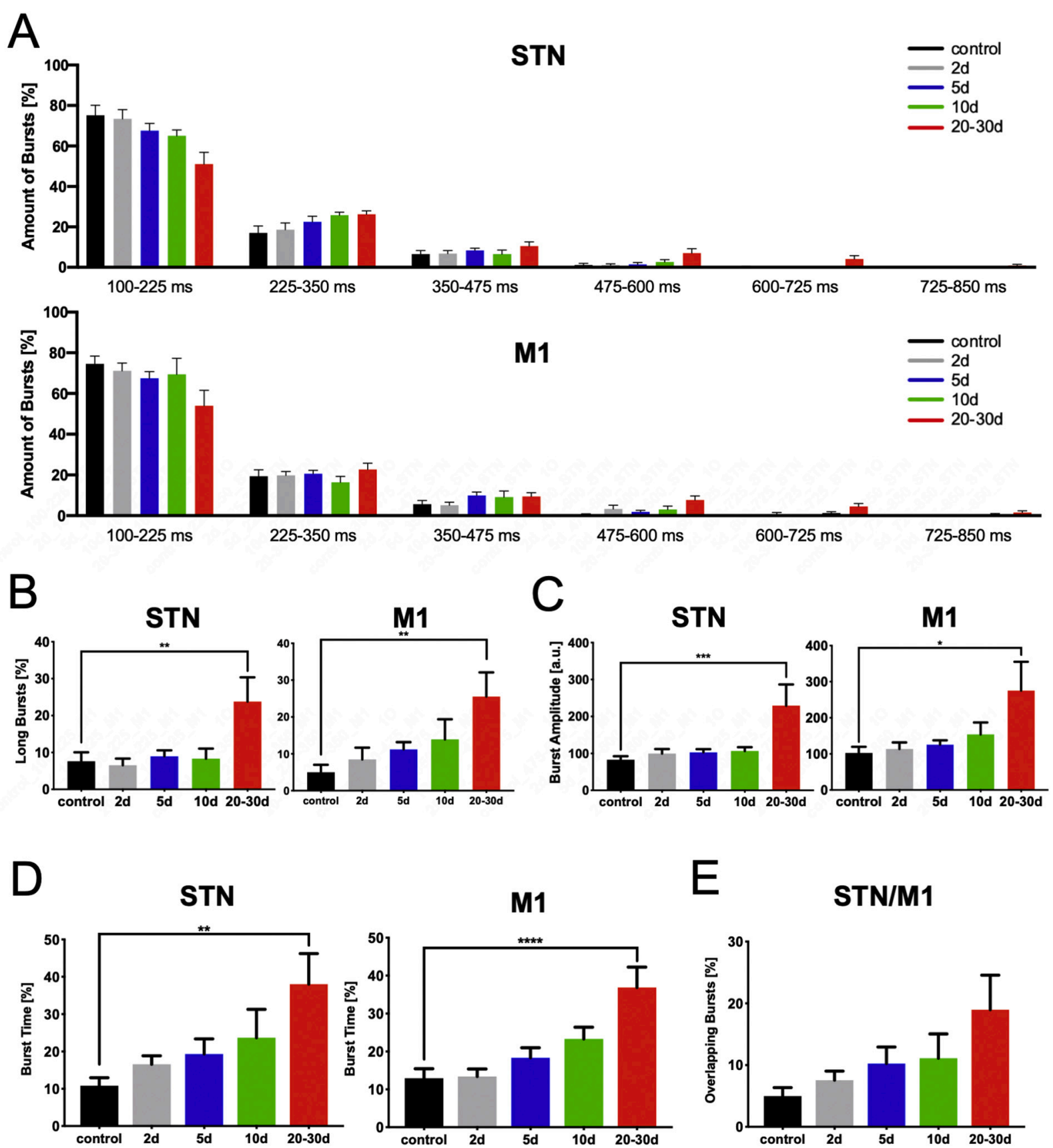

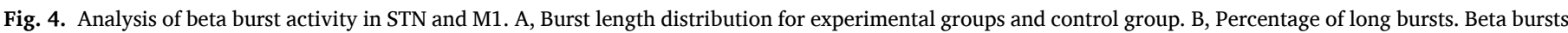
>350 ms were considered as long bursts. C, Burst amplitudes. D, Time spent in bursts of a $50 \mathrm{~s}$ epoch. E, Overlapping bursts in STN and M1.

STN $_{\text {beta-drag: } \rho=-0.393, p}<0.01$; Fig. 5C). In contrast, M1 mean beta power was not correlated with motor impairment (Fig. 5D).

\section{Discussion}

In this study, we investigated the interrelation of motor impairment, electrophysiological network changes and histology during the ongoing neurodegeneration of the nigrostriatal dopamine system in the 6-OHDA rat model of PD. We demonstrated four main findings: (1) Significant increases in beta power emerged in STN before they could be detected in M1. (2) The percentage of longer beta bursts increased over time. (3) Subthalamic but not cortical beta power was strongly correlated with the degeneration of dopaminergic striatal fibers and nigral dopaminergic neurons. (4) Subthalamic but not cortical beta power was correlated with motor impairment.
4.1.1. The role of the STN in the cortico-basal ganglia network

Very important findings of our study were the highly significant correlations between beta oscillations in the STN and the progressive loss of dopaminergic striatal fibers and nigral cells. Thus, our data supports prior evidence from human PD patients and animal models of PD that enhanced synchrony in the beta band is mediated by a lack of dopamine (Brown 2007; Stein and Bar-Gad 2013). Furthermore, we are the first to demonstrate a strong relation between the amplitude of beta activity and the extent of the degeneration of the nigrostriatal dopamine system. Perspectively, our finding might be of importance for the ongoing development of adaptive DBS techniques, especially when used in younger patients (Priori et al. 2013; Schuepbach et al. 2013). 

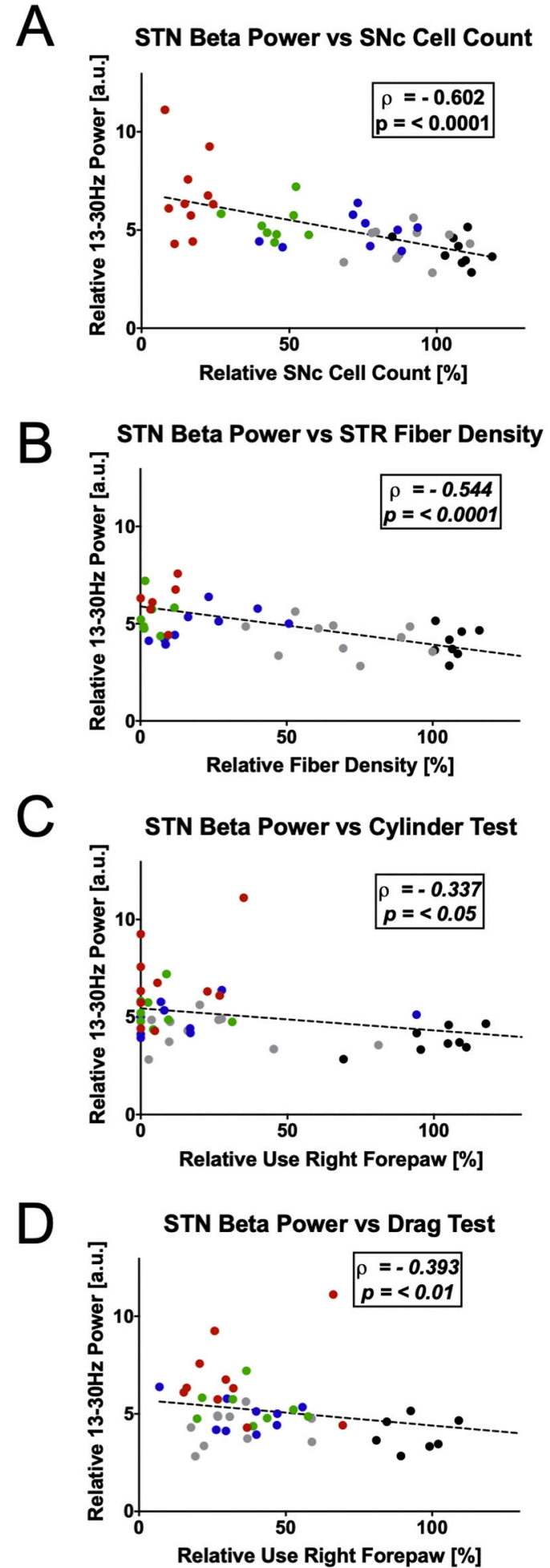
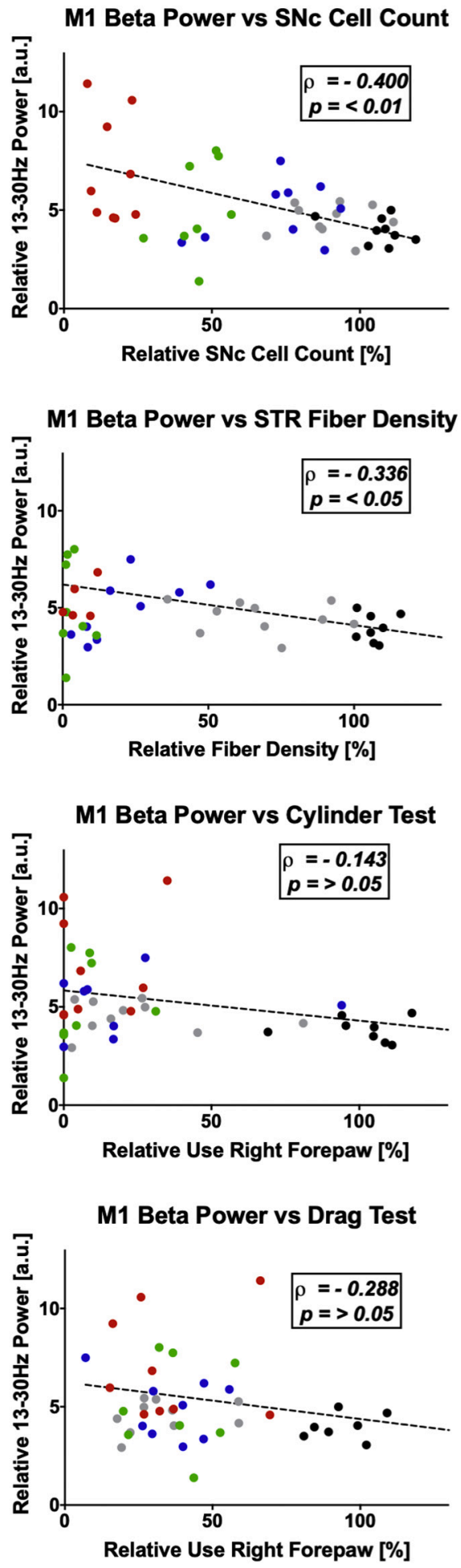

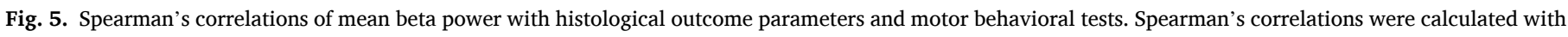

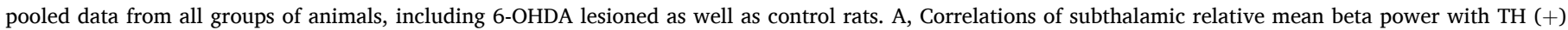

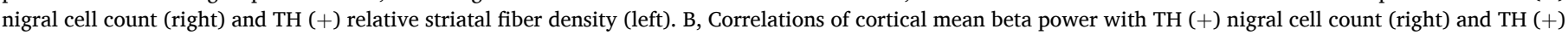

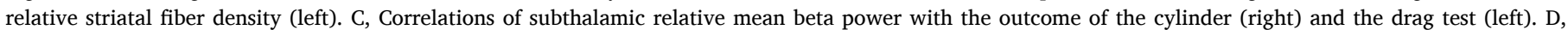

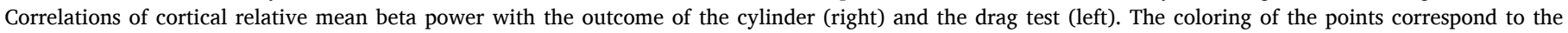
different groups of animals with black for control and grey, blue, green and red for the animals 2, 5, 10 and 20-30 days after the injection of 6-OHDA.

Significant elevation of mean beta power started earlier in STN than in M1. Subthalamic but not cortical beta power showed strong correlations not only with histological markers of dopaminergic neurodegeneration, but also motor impairment. This points to a prominent role of the STN within the cortico-basal ganglia network, which is supported by recent studies (Baunez et al. 2011; Bevan et al. 2002; Deffains et al. 2016; Holgado et al. 2010). Although we cannot localize the generator of exaggerated beta band activity in PD models, our data 
further support the notion that beta oscillations emerge involving predominantly the STN (Bevan et al. 2002; Holgado et al. 2010; Mallet et al. 2008a; Plenz and Kital 1999). Our data do not point to M1 as a primary generator of exaggerated beta in parkinsonism, which is in line with our recent study demonstrating enhanced subthalamic beta oscillations in the absence of cortical beta power changes in the reserpine model of PD (Beck et al. 2016).

\subsubsection{Relevance of long beta bursts}

Increased long beta bursts have been related to the OFF state in PD patients (Lofredi et al. 2018a; Tinkhauser et al. 2017b). Our results of enhanced long burst activity during progressive dopamine depletion add to the current characterization of burst activity in PD models relating the change in burst pattern to the progressive neurodegeneration. Additionally, we observed a decrease in shorter bursts, which are considered physiological, that occurred with further dopamine depletion. In line with this, in PD patients an increase of shorter bursts has been found in the levodopa ON-condition compared to the OFF-condition as well as during adaptive DBS (Tinkhauser et al. 2017a; Tinkhauser et al. 2017b), both that could be considered as more normalized states. We could further demonstrate that changes in burst characteristics were similar in M1 and STN pointing to a network effect. The increased burst time with longer beta bursts may impair information coding on the network level leading to motor symptoms in PD (Feingold et al. 2015). Our findings underline the relevance of long beta bursts as a pathophysiological marker in PD. If beta burst changes occur equally in M1 and STN also in PD patients, it could be discussed as a potential marker for adaptive stimulation using motor cortical activity as a trigger signal.

\subsubsection{Limitations}

In our model, akinesia was present two days after the 6-OHDA injection, when no change in beta power was detectable. Hence, our data do not support the hypothesis that beta oscillations and motor impairment in PD are directly linked. Our findings are in line with previously published experimental studies on the MPTP non-human primate model of $\mathrm{PD}$, in which a concurrence of enhanced beta power and motor impairment could not be proven (Connolly et al. 2015; Devergnas et al. 2014; Leblois et al. 2007; Muralidharan et al. 2016).

The different pathomechanisms between toxin-based animal models of PD and PD in humans may limit comparability, as the neurotoxin 6OHDA may have caused severe metabolic dysfunctions of SNc neurons before apparent structural changes were detectable (Bartholini et al. 1970). Since we did not record from all nodes of the network and did not continuously monitor motor behavior and local field potentials, we might have missed the exact time point of the emergence of enhanced beta synchrony.

We performed our recordings under urethane anesthesia, which may alter oscillation patterns. However, as we found highly significant correlations between the progression of subthalamic beta power and akinesia over time, we believe that the present data set still provides valuable new insights into the pathophysiology of PD.

Our definition of beta bursts as signals that cross the 75th percentile threshold has a high impact on resulting burst parameters: Choosing a low threshold includes more short low-amplitude bursts than choosing a high threshold. In contrast, high-amplitude bursts are always included. In the study of Tinkhauser et al. (2017a), the authors implemented a within-subjects design and defined the threshold per subject, but applied the same threshold in all conditions. This procedure is reasonable to account for between-subjects variance in burst character that is not related to the experimental conditions. In the study at hand, this was not possible due to a between-subjects design. Instead, we assumed that unrelated burst variance would be randomly distributed among subjects of different groups. Thus, to avoid any confounds between threshold definition and experimental group, we decided to apply the same threshold-the average of all animals of all conditions-to all recordings.

\section{Conclusions}

In the present study we provide evidence for an important functional role of excessive beta oscillations in the pathophysiology of PD. We are the first to show a highly significant correlation of enhanced STN beta activity and dopaminergic neurodegeneration. Thus, our data supports the prevailing hypothesis that beta band oscillations and burst activity could be a useful feedback biomarker for adaptive DBS (Petrucci et al. 2020; Pina-Fuentes et al. 2020; Velisar et al. 2019).

Supplementary data to this article can be found online at https://doi. org/10.1016/j.expneurol.2020.113513.

\section{Funding}

This work was supported by grants from the German Research Foundation/Deutsche Forschungsgemeinschaft (GE 2629/1-1).

\section{CRediT authorship contribution statement}

Jens K. Haumesser: Methodology, Investigation, Formal analysis, Software, Visualization, Writing - original draft, Writing - review \& editing. Maximilian H. Beck: Investigation, Formal analysis, Writing review \& editing. Franziska Pellegrini: Formal analysis, Software, Visualization, Writing - review \& editing. Johanna Kühn: Formal analysis, Visualization, Writing - review \& editing. Wolf-Julian Neumann: Formal analysis, Software, Visualization, Validation, Writing review \& editing. Jennifer Altschüler: Formal analysis, Writing - review \& editing. Daniel Harnack: Conceptualization, Methodology, Writing - review \& editing. Andreas Kupsch: Conceptualization, Methodology, Writing - review \& editing. Vadim V. Nikulin: Formal analysis, Visualization, Software, Writing - review \& editing. Andrea A. Kühn: Funding acquisition, Resources, Validation, Visualization, Writing - review \& editing. Christoph van Riesen: Conceptualization, Methodology, Validation, Software, Formal analysis, Investigation, Visualization, Resources, Supervision, Writing - original draft, Writing review \& editing, Project administration, Funding acquisition.

\section{Declaration of Competing Interest}

none.

\section{References}

Abdi, A., Mallet, N., Mohamed, F.Y., Sharott, A., Dodson, P.D., Nakamura, K.C., Suri, S., Avery, S.V., Larvin, J.T., Garas, F.N., Garas, S.N., Vinciati, F., Morin, S., Bezard, E., Baufreton, J., Magill, P.J., 2015. Prototypic and arkypallidal neurons in the dopamine-intact external globus pallidus. J. Neurosci. 35, 6667-6688.

Arlotti, M., Marceglia, S., Foffani, G., Volkmann, J., Lozano, A.M., Moro, E. Cogiamanian, F., Prenassi, M., Bocci, T., Cortese, F., Rampini, P., Barbieri, S. Priori, A., 2018. Eight-hours adaptive deep brain stimulation in patients with Parkinson disease. Neurology 90, e971-e976.

Bartholini, G., Richards, J.G., Pletscher, A., 1970. Dissociation between biochemical and ultrastructural effects of 6-hydroxydopamine in rat brain. Experientia 26, 142-144.

Baunez, C., Yelnik, J., Mallet, L., 2011. Six questions on the subthalamic nucleus: lessons from animal models and from stimulated patients. Neuroscience 198, 193-204.

Beck, M.H., Haumesser, J.K., Kuhn, J., Altschuler, J., Kuhn, A.A., van Riesen, C., 2016. Short- and long-term dopamine depletion causes enhanced beta oscillations in the cortico-basal ganglia loop of parkinsonian rats. Exp. Neurol. 286, 124-136.

Bevan, M.D., Magill, P.J., Terman, D., Bolam, J.P., Wilson, C.J., 2002. Move to the rhythm: oscillations in the subthalamic nucleus-external globus pallidus network. Trends Neurosci. 25, 525-531.

Blandini, F., Armentero, M.T., 2012. Animal models of Parkinson's disease. FEBS J. 279, $1156-1166$.

Blandini, F., Levandis, G., Bazzini, E., Nappi, G., Armentero, M.T., 2007. Time-course of nigrostriatal damage, basal ganglia metabolic changes and behavioural alterations following intrastriatal injection of 6-hydroxydopamine in the rat: new clues from an old model. Eur. J. Neurosci. 25, 397-405.

Brown, P., 2007. Abnormal oscillatory synchronisation in the motor system leads to impaired movement. Curr. Opin. Neurobiol. 17, 656-664.

Brown, P., Oliviero, A., Mazzone, P., Insola, A., Tonali, P., Di Lazzaro, V., 2001. Dopamine dependency of oscillations between subthalamic nucleus and pallidum in Parkinson's disease. J. Neurosci. 21, 1033-1038. 
Cagnan, H., Mallet, N., Moll, C.K.E., Gulberti, A., Holt, A.B., Westphal, M., Gerloff, C., Engel, A.K., Hamel, W., Magill, P.J., Brown, P., Sharott, A., 2019. Temporal evolution of beta bursts in the parkinsonian cortical and basal ganglia network. Proc. Natl. Acad. Sci. U. S. A. 116, 16095-16104.

Chen, C.C., Lin, W.Y., Chan, H.L., Hsu, Y.T., Tu, P.H., Lee, S.T., Chiou, S.M., Tsai, C.H. Lu, C.S., Brown, P., 2011. Stimulation of the subthalamic region at $20 \mathrm{~Hz}$ slows the development of grip force in Parkinson's disease. Exp. Neurol. 231, 91-96.

Connolly, A.T., Jensen, A.L., Bello, E.M., Netoff, T.I., Baker, K.B., Johnson, M.D., Vitek, J. L., 2015. Modulations in oscillatory frequency and coupling in globus pallidus with increasing parkinsonian severity. J. Neurosci. 35, 6231-6240.

Deffains, M., Iskhakova, L., Katabi, S., Haber, S.N., Israel, Z., Bergman, H., 2016. Subthalamic, not striatal, activity correlates with basal ganglia downstream activity in normal and parkinsonian monkeys. Elife 5.

Degos, B., Deniau, J.M., Chavez, M., Maurice, N., 2009. Chronic but not acute dopaminergic transmission interruption promotes a progressive increase in cortical beta frequency synchronization: relationships to vigilance state and akinesia. Cereb. Cortex 19, 1616-1630.

Delaville, C., McCoy, A.J., Gerber, C.M., Cruz, A.V., Walters, J.R., 2015. Subthalamic nucleus activity in the awake hemiparkinsonian rat: relationships with motor and cognitive networks. J. Neurosci. 35, 6918-6930.

Devergnas, A., Pittard, D., Bliwise, D., Wichmann, T., 2014. Relationship between oscillatory activity in the cortico-basal ganglia network and parkinsonism in MPTPtreated monkeys. Neurobiol. Dis. 68, 156-166.

Doyle, L.M., Kuhn, A.A., Hariz, M., Kupsch, A., Schneider, G.H., Brown, P., 2005. Levodopa-induced modulation of subthalamic beta oscillations during self-paced movements in patients with Parkinson's disease. Eur. J. Neurosci. 21, 1403-1412.

Eusebio, A., Brown, P., 2009. Synchronisation in the beta frequency-band-the bad boy of parkinsonism or an innocent bystander? Exp. Neurol. 217, 1-3.

Eusebio, A., Chen, C.C., Lu, C.S., Lee, S.T., Tsai, C.H., Limousin, P., Hariz, M., Brown, P., 2008. Effects of low-frequency stimulation of the subthalamic nucleus on movement in Parkinson's disease. Exp. Neurol. 209, 125-130.

Eusebio, A., Thevathasan, W., Doyle Gaynor, L., Pogosyan, A., Bye, E., Foltynie, T., Zrinzo, L., Ashkan, K., Aziz, T., Brown, P., May 2009. Deep brain stimulation can suppress pathological synchronisation in parkinsonian patients. J. Neurol. Neurosurg. Psychiatry 217 (1), 1-3.

Feingold, J., Gibson, D.J., DePasquale, B., Graybiel, A.M., 2015. Bursts of beta oscillation differentiate postperformance activity in the striatum and motor cortex of monkeys performing movement tasks. Proc. Natl. Acad. Sci. U. S. A. 112, 13687-13692.

Hammond, C., Bergman, H., Brown, P., 2007. Pathological synchronization in Parkinson's disease: networks, models and treatments. Trends Neurosci. 30, 357-364.

Haumesser, J.K., Kuhn, J., Guttler, C., Nguyen, D.H., Beck, M.H., Kuhn, A.A., van Riesen, C., 2017. Acute in Vivo Electrophysiological Recordings of Local Field Potentials and Multi-Unit Activity from the Hyperdirect Pathway in Anesthetized Rats ( $J$ Vis Exp).

Holgado, A.J., Terry, J.R., Bogacz, R., 2010. Conditions for the generation of beta oscillations in the subthalamic nucleus-globus pallidus network. J. Neurosci. 30, $12340-12352$.

Kuhn, A.A., Williams, D., Kupsch, A., Limousin, P., Hariz, M., Schneider, G.H., Yarrow, K., Brown, P., 2004. Event-related beta desynchronization in human subthalamic nucleus correlates with motor performance. Brain 127, 735-746.

Kuhn, A.A., Trottenberg, T., Kivi, A., Kupsch, A., Schneider, G.H., Brown, P., 2005. The relationship between local field potential and neuronal discharge in the subthalamic nucleus of patients with Parkinson's disease. Exp. Neurol. 194, 212-220.

Kuhn, A.A., Doyle, L., Pogosyan, A., Yarrow, K., Kupsch, A., Schneider, G.H., Hariz, M.I. Trottenberg, T., Brown, P., 2006. Modulation of beta oscillations in the subthalamic area during motor imagery in Parkinson's disease. Brain 129, 695-706.

Kuhn, A.A., Tsui, A., Aziz, T., Ray, N., Brucke, C., Kupsch, A., Schneider, G.H., Brown, P., 2009. Pathological synchronisation in the subthalamic nucleus of patients with Parkinson's disease relates to both bradykinesia and rigidity. Exp. Neurol. 215, 380-387.

Leblois, A., Meissner, W., Bioulac, B., Gross, C.E., Hansel, D., Boraud, T., 2007. Late emergence of synchronized oscillatory activity in the pallidum during progressive parkinsonism. Eur. J. Neurosci. 26, 1701-1713.

Levy, R., Ashby, P., Hutchison, W.D., Lang, A.E., Lozano, A.M., Dostrovsky, J.O., 2002. Dependence of subthalamic nucleus oscillations on movement and dopamine in Parkinson's disease. Brain 125, 1196-1209.

Lindemann, C., Alam, M., Krauss, J.K., Schwabe, K., 2013. Neuronal activity in the medial associative-limbic and lateral motor part of the rat subthalamic nucleus and the effect of 6-hydroxydopamine-induced lesions of the dorsolateral striatum. J. Comp. Neurol. 521, 3226-3240.

Little, S., Pogosyan, A., Neal, S., Zavala, B., Zrinzo, L., Hariz, M., Foltynie, T., Limousin, P., Ashkan, K., Fitzgerald, J., Green, A.L., Aziz, T.Z., Brown, P., September 2013. Adaptive deep brain stimulation in advanced Parkinson disease. Ann. Neurol. 74 (3), 449-457.

Little, S., Beudel, M., Zrinzo, L., Foltynie, T., Limousin, P., Hariz, M., Neal, S., Cheeran, B., Cagnan, H., Gratwicke, J., Aziz, T.Z., Pogosyan, A., Brown, P., 2015. Bilateral adaptive deep brain stimulation is effective in Parkinson's disease. J. Neurol. Neurosurg. Psychiatry 87, 717-721.

Lofredi, R., Neumann, W.J., Bock, A., Horn, A., Huebl, J., Siegert, S., Schneider, G.H., Krauss, J.K., Kuhn, A.A., 2018a. Dopamine-dependent scaling of subthalamic gamma bursts with movement velocity in patients with Parkinson's disease. Elife 7.

Lofredi, R., Neumann, W.J., Brucke, C., Huebl, J., Krauss, J.K., Schneider, G.H., Kuhn, A. A., 2018b. Pallidal beta bursts in Parkinson's disease and dystonia. Elife 7, e31895.
Magill, P.J., Bolam, J.P., Bevan, M.D., 2000. Relationship of activity in the subthalamic nucleus-globus pallidus network to cortical electroencephalogram. J. Neurosci. 20, 820-833.

Magill, P.J., Bolam, J.P., Bevan, M.D., 2001. Dopamine regulates the impact of the cerebral cortex on the subthalamic nucleus-globus pallidus network. Neuroscience 106, 313-330.

Magill, P.J., Sharott, A., Bolam, J.P., Brown, P., 2006. Delayed synchronization of activity in cortex and subthalamic nucleus following cortical stimulation in the rat. J. Physiol. 574, 929-946.

Mallet, N., Pogosyan, A., Marton, L.F., Bolam, J.P., Brown, P., Magill, P.J., 2008a. Parkinsonian beta oscillations in the external globus pallidus and their relationship with subthalamic nucleus activity. J. Neurosci. 28, 14245-14258.

Mallet, N., Pogosyan, A., Sharott, A., Csicsvari, J., Bolam, J.P., Brown, P., Magill, P.J., 2008b. Disrupted dopamine transmission and the emergence of exaggerated beta oscillations in subthalamic nucleus and cerebral cortex. J. Neurosci. 28, 4795-4806.

Meredith, G.E., Kang, U.J., 2006. Behavioral models of Parkinson's disease in rodents: a new look at an old problem. Mov. Disord. 21, 1595-1606.

Muralidharan, A., Jensen, A.L., Connolly, A., Hendrix, C.M., Johnson, M.D., Baker, K.B., Vitek, J.L., 2016. Physiological changes in the pallidum in a progressive model of Parkinson's disease: are oscillations enough? Exp. Neurol. 279, 187-196.

Neumann, W.J., Degen, K., Schneider, G.H., Brucke, C., Huebl, J., Brown, P., Kuhn, A.A., 2016. Subthalamic synchronized oscillatory activity correlates with motor impairment in patients with Parkinson's disease. Mov. Disord. 31, 1748-1751.

Neumann, W.J., Staub-Bartelt, F., Horn, A., Schanda, J., Schneider, G.H., Brown, P., Kuhn, A.A., 2017. Long term correlation of subthalamic beta band activity with motor impairment in patients with Parkinson's disease. Clin. Neurophysiol. 128, 2286-2291.

Oswal, A., Brown, P., Litvak, V., 2013. Synchronized neural oscillations and the pathophysiology of Parkinson's disease. Curr. Opin. Neurol. 26, 662-670.

Paxinos, G., Watson, C., 2013. The Rat Brain in Stereotaxix Coordinates 7th Edition. Academic Press.

Petrucci, M.N., Neuville, R.S., Afzal, M.F., Velisar, A., Anidi, C.M., Anderson, R.W., Parker, J.E., O’Day, J.J., Wilkins, K.B., Bronte-Stewart, H.M., 2020. Neural closedloop deep brain stimulation for freezing of gait. Brain Stimul 13, 1320-1322.

Pina-Fuentes, D., van Dijk, J.M.C., van Zijl, J.C., Moes, H.R., van Laar, T., Oterdoom, D.L. M., Little, S., Brown, P., Beudel, M., 2020. Acute effects of adaptive deep brain stimulation in Parkinson's disease. Brain Stimul 13, 1507-1516.

Plenz, D., Kital, S.T., 1999. A basal ganglia pacemaker formed by the subthalamic nucleus and external globus pallidus. Nature 400, 677-682.

Priori, A., Foffani, G., Rossi, L., Marceglia, S., 2013. Adaptive deep brain stimulation (aDBS) controlled by local field potential oscillations. Exp. Neurol. 245, 77-86.

Ray, N.J., Jenkinson, N., Wang, S., Holland, P., Brittain, J.S., Joint, C., Stein, J.F., Aziz, T., 2008. Local field potential beta activity in the subthalamic nucleus of patients with Parkinson's disease is associated with improvements in bradykinesia after dopamine and deep brain stimulation. Exp. Neurol. 213, 108-113.

Schallert, T., Fleming, S.M., Leasure, J.L., Tillerson, J.L., Bland, S.T., 2000. CNS plasticity and assessment of forelimb sensorimotor outcome in unilateral rat models of stroke, cortical ablation, parkinsonism and spinal cord injury. Neuropharmacology 39, 777-787.

Schuepbach, W.M., Rau, J., Knudsen, K., Volkmann, J., Krack, P., Timmermann, L., Halbig, T.D., Hesekamp, H., Navarro, S.M., Meier, N., Falk, D., Mehdorn, M., Paschen, S., Maarouf, M., Barbe, M.T., Fink, G.R., Kupsch, A., Gruber, D., Schneider, G.H., Seigneuret, E., Kistner, A., Chaynes, P., Ory-Magne, F., Brefel Courbon, C., Vesper, J., Schnitzler, A., Wojtecki, L., Houeto, J.L., Bataille, B., Maltete, D., Damier, P., Raoul, S., Sixel-Doering, F., Hellwig, D., Gharabaghi, A., Kruger, R., Pinsker, M.O., Amtage, F., Regis, J.M., Witjas, T., Thobois, S., Mertens, P., Kloss, M., Hartmann, A., Oertel, W.H., Post, B., Speelman, H., Agid, Y., SchadeBrittinger, C., Deuschl, G., 2013. Neurostimulation for Parkinson's disease with early motor complications. N. Engl. J. Med. 368, 610-622.

Sharott, A., Magill, P.J., Harnack, D., Kupsch, A., Meissner, W., Brown, P., 2005. Dopamine depletion increases the power and coherence of beta-oscillations in the cerebral cortex and subthalamic nucleus of the awake rat. Eur. J. Neurosci. 21 , 1413-1422.

Shimamoto, S.A., Ryapolova-Webb, E.S., Ostrem, J.L., Galifianakis, N.B., Miller, K.J., Starr, P.A., 2013. Subthalamic nucleus neurons are synchronized to primary motor cortex local field potentials in Parkinson's disease. J. Neurosci. 33, 7220-7233.

Stein, E., Bar-Gad, I., 2013. Beta oscillations in the cortico-basal ganglia loop during parkinsonism. Exp. Neurol. 245, 52-59.

Steiner, B., Winter, C., Blumensath, S., Paul, G., Harnack, D., Nikkhah, G., Kupsch, A., 2008. Survival and functional recovery of transplanted human dopaminergic neurons into hemiparkinsonian rats depend on the cannula size of the implantation instrument. J. Neurosci. Methods 169, 128-134.

Steriade, M., 2000. Corticothalamic resonance, states of vigilance and mentation. Neuroscience 101, 243-276.

Timmermann, L., Fink, G.R., 2011. Pathological network activity in Parkinson's disease: from neural activity and connectivity to causality? Brain 134, 332-334.

Tinkhauser, G., Pogosyan, A., Little, S., Beudel, M., Herz, D.M., Tan, H., Brown, P., 2017a. The modulatory effect of adaptive deep brain stimulation on beta bursts in Parkinson's disease. Brain 140, 1053-1067.

Tinkhauser, G., Pogosyan, A., Tan, H., Herz, D.M., Kuhn, A.A., Brown, P., 2017b. Beta burst dynamics in Parkinson's disease OFF and ON dopaminergic medication. Brain 140, 2968-2981. 
Velisar, A., Syrkin-Nikolau, J., Blumenfeld, Z., Trager, M.H., Afzal, M.F., Prabhakar, V., Bronte-Stewart, H., 2019. Dual threshold neural closed loop deep brain stimulation in Parkinson disease patients. Brain Stimul 12, 868-876.

Weinberger, M., Mahant, N., Hutchison, W.D., Lozano, A.M., Moro, E., Hodaie, M., Lang, A.E., Dostrovsky, J.O., 2006. Beta oscillatory activity in the subthalamic nucleus and its relation to dopaminergic response in Parkinson's disease.

J. Neurophysiol. 96, 3248-3256.

van Wijk, B.C., Beudel, M., Jha, A., Oswal, A., Foltynie, T., Hariz, M.I., Limousin, P., Zrinzo, L., Aziz, T.Z., Green, A.L., Brown, P., Litvak, V., 2016. Subthalamic nucleus phase-amplitude coupling correlates with motor impairment in Parkinson's disease. Clin. Neurophysiol. 127, 2010-2019. 